\title{
RELAÇÕES ENTRE A DISTRIBUIÇÃO ESPACIAL DA COVID-19 E A DINÂMICA DAS INTERAÇÕES ESPACIAIS NO ESTADO DO RIO GRANDE DO SUL
}

\section{RELATIONSHIP BETWEEN SPATIAL DISTRIBUTION OF COVID-19 AND DYNAMICS OF SPACE INTERACTIONS IN RIO GRANDE DO SUL STATE}

\author{
Rodrigo Giraldi Cocco \\ Doutor em Geografia pela Universidade Autônoma de Barcelona (UAB) e \\ Universidade Federal de Santa Catarina (UFSC) \\ rodrigog.cocco@gmail.com \\ Erika Collischonn \\ Doutora em Geografia pela Universidade Federal de Santa Catarina (UFSC) \\ Professora Associada da Universidade Federal de Pelotas (UFPEL) \\ ecollischonn@gmail.com \\ Maurício Meurer \\ Doutor em Geografia pela Universidade Lumière Lyon 2 \\ Professor Associado da Universidade Federal de Pelotas (UFPEL) \\ mauriciomeurer@yahoo.com.br
}

\begin{abstract}
RESUMO
O presente trabalho tem por objetivo analisar as relações existentes entre a distribuição espaço-temporal dos casos de COVID-19, as mobilidades inter-regionais e pendulares e as atividades produtivas no estado do Rio Grande do Sul. A metodologia teve por base a análise conjunta de dados dos números de casos de infecção, do tempo de confirmação do primeiro caso por localidade, das infraestruturas e serviços de transporte e das atividades econômicas no território sul-rio-grandense. A pesquisa demonstrou que essas relações são verossímeis, exibindo, portanto, a complexidade do elo existente entre as interações espaciais e a difusão espacial do SARS-CoV-2, o vírus causador da doença. O trabalho reforça a importância dos estudos interdisciplinares, em especial na Geografia da Saúde, ao levantar questões sobre os transportes e as interações espaciais, as atividades econômicas nas diferentes regiões do estado e as características físicas que envolvem a temperatura interna dos ambientes de produção e circulação. O estudo também põe à mostra a fragilidade do Estado neoliberal na vigilância, gestão e planejamento estratégico dos serviços, infraestruturas de transporte e atividades produtivas, em meio aos saltos multiescalares dos patógenos de alto contágio na rede urbana. Ao mesmo tempo, demonstra que a difusão espacial do SARS-CoV-2 e a localização dos casos de COVID-19 tem obedecido relativamente aos padrões dos volumes e frequências de deslocamentos conhecidamente regionais em eixos rodoviários, bem como características de certas atividades produtivas e de reprodução social.
\end{abstract}

Palavras-chave: COVID-19. Mobilidade. Transportes. Ambiente de trabalho.

\begin{abstract}
The present work aims to analyze the existing relationships between the space-time distribution of COVID19, interregional and commuting mobilities and productive activities in the state of Rio Grande do Sul. The methodology was based on the joint data analysis of numbers of contamination cases, the confirmation time of the first case by location, the infrastructure and transport services and the economic activities in the Rio Grande do Sul territory. Research has shown that these relationships are credible, thus exhibiting the complexity of the link between spatial interactions and the spread of SARS-Cov-2, virus that causes the disease. The work reinforces the importance of interdisciplinary studies, especially in Health Geography, by raising questions about transport and spatial interactions, economic activities in different regions of the state and physical characteristics that involve the internal temperature of the production and circulation environments. The study also shows the fragility of the neoliberal state in the surveillance, management and strategic planning of services, transport infrastructures and productive activities, in the midst
\end{abstract}

Recebido em: 02/05/2020

Aceito para publicação em: 21/05/2020. 
of the multiscale leaps of highly contagious pathogens in the urban network. At the same time, it demonstrates that the spatial diffusion of SARS-CoV-2 and the location of COVID-19 cases has obeyed the patterns of volumes and frequencies of known regional displacements on road axes, as well as characteristics of certain productive and social reproduction activities.

Keywords: COVID-19. Mobility. Transportation. Work environment.

\section{INTRODUÇÃO}

Dentre os denominados equipamentos de reprodução social (JARAMILLO, 1983), destacam-se aqueles ligados direta ou indiretamente à saúde pública, um dos principais direitos sociais entregues à lógica neoliberal por governos de todo o mundo. Mesmo em meio à rápida disseminação da COVID-19 (Corona Virus Disease), doença causada pelo vírus SARS-CoV-2 (Severe Acute Respiratory Syndrome Coronavirus 2) ${ }^{2}$, as instituições estatais responsáveis pelo controle da pandemia têm sido negligentes no que se refere ao seu caráter multiescalar. Principalmente nos países que implementaram mais fortemente políticas de "austeridade". Vale ressaltar que, em uma economia globalizada, as escalas da economia e da vida cotidiana se entrecruzam, conferindo um grau ampliado de periculosidade ao atual contexto de pandemia (BRENNER, 2001; SPOSITO; GUIMARÃES, 2020;). Assim, o receituário neoliberal da "austeridade" e da "não intervenção do Estado", que tem afetado duramente os equipamentos de saúde pública (CASAS, 2009; GADELHA, 2018), acaba por afetar também a capacidade de ação do Estado sobre outras atividades econômicas. É o caso dos sistemas de comunicação e transportes, e de algumas atividades econômicas em especial, como das indústrias intensivas em mão de obra, de bens duráveis e semiduráveis, e de cadeias produtivas da agropecuária, também envolvidas no processo de transmissão do vírus ${ }^{3}$.

Os sistemas de transporte jogam um papel fundamental na atual crise, na medida em que articulam as múltiplas escalas de dispersão do vírus. Ainda que os primeiros casos de contaminação pelo novo coronavírus tenham se originado em viagens ao exterior, mediante o transporte aéreo, sua disseminação nas redes urbanas regionais/estaduais, no Brasil, tem se dado - além dos voos regionais - também através de sistemas de transporte rodoviários, haja vista que muitos núcleos urbanos são conectados à rede apenas por esse modal. As atividades produtivas em stricto senso também têm um papel preponderante na difusão do SARS-CoV-2 e assim, da COVID-19, na medida em que demandam proximidade entre pessoas - trabalhadores em uma linha de produção, executivos e técnicos que realizam reuniões etc. - que, em muitos casos, se dão em ambientes fechados, onde ocorrem emissões de partículas nos processos produtivos, com pouca ventilação e/ou, principalmente, sob baixas temperaturas. Ressalta-se também a baixa oferta de EPIs adequados aos trabalhadores, em um contexto de pandemia.

A complexidade das interações espaciais das quais participam os transportes e a produção de mercadorias é notória no caso do estado do Rio Grande do Sul, recorte desse estudo. No tocante aos transportes, destacamos a importância tanto daqueles deslocamentos que se dão a distâncias maiores dentro do território sul-rio-grandense, ou seja, os inter-regionais, como aqueles que ocorrem dentro de uma mesma região, portanto, intrarregionais. Vale ressaltar que nesse último caso, muitos deslocamentos são mobilidades pendulares, isto é, de frequência cotidiana. No que se refere à produção, destacamos a importância tanto das indústrias de bens duráveis e semiduráveis, presentes nos espaços industriais do Rio Grande do Sul, quanto na indústria alimentícia, em especial na cadeia produtiva das carnes, englobando a pecuária e seus processos "dentro e fora da porteira", como abate e frigorificação.

Assim, as interações espaciais não são meros deslocamentos, possuem motivos, tempos de realização, tempos de permanência nos estabelecimentos de destino, frequências, volumes quantitativos, níveis de conforto, origens e destinos e, por fim, indivíduos que entram em contato

\footnotetext{
2 Também é denominado em alguns meios, como "novo coronavírus".

3 Obviamente podemos mencionar outras atividades que funcionam inclusive em período de quarentena, como certas atividades estatais (bancos públicos, correios); bancos privados; supermercados e farmácias; transportes públicos intraurbanos e outros serviços urbanos que podem ser focos de difusão do vírus, dadas as suas características de contato interpessoal, ambiente climatizado, etc.

DOl:http://dx.doi.org/10.14393/Hygeia0054406 $\quad$ Hygeia Edição Especial: Covid-19, Jun./2020 p.183 - 192, pág.184
} 
entre si, gerando transformações nos elementos que são o objeto de sua reunião e neles mesmos (COCCO; SILVEIRA, 2011). O forte caráter complementar dessas interações faz com que a tarefa de cessá-las temporariamente em contexto de pandemia seja muito complexa - mas necessária para o chamado "achatamento da curva de contaminação" -, exigindo um "esforço de guerra" que o Estado brasileiro tem se eximido de fazer, até o momento. O presente artigo tem por objetivo central analisar as relações existentes entre os padrões de distribuição espaço-temporal da COVID-19, as infraestruturas de transporte e as atividades econômicas no estado do Rio Grande do Sul, sobretudo aquelas mais associadas ao problema, como é o caso dos frigoríficos. A partir dessas relações, se busca uma aproximação dos padrões de difusão espacial do patógeno SARS-CoV-2.

\section{METODOLOGIA}

O estudo foi baseado na análise de cartogramas que exibem a distribuição espacial e temporal da COVID-19 no estado do Rio Grande do Sul, sobrepondo esses dados à localização das infraestruturas de transporte e de estruturas produtivas presentes nas diferentes regiões do estado. A visualização, consulta, interpolação e análise foram elaboradas no software livre QGIS 2.18. Os dados sobre casos confirmados de COVID-19 foram obtidos nas bases de dados online do Centro de Operações de Emergências (COE) da Secretaria da Saúde do Rio Grande do Sul. As representações cartográficas da estrutura territorial brasileira em nível de estado e município foram as disponibilizadas pelo IBGE, e as representações de vias de circulação e estruturas relacionadas são do Ministério da Infraestrutura e da Secretaria da Infraestrutura e Meio Ambiente do Rio Grande do Sul (todos referenciados ao Sistema Geodésico Brasileiro SIRGAS 2000). Da base de dados online do Departamento de Inspeção de Produtos de Origem Animal do Ministério da Agricultura, foram obtidos a razão social, o endereço e o município nos qual se localizam os frigoríficos do estado. Com base no endereço, foi possível definir a referência geográfica de cada frigorífico, de forma que se obteve uma camada de dados pontuais, contendo o nome e a tipologia de cada unidade. Para a representação da distribuição espaço-temporal da COVID-19 foi utilizado o centróide do município como amostra para interpolação. Este centróide continha um atributo com o número de dias decorridos desde o primeiro caso de COVID-19 até a data mapeada. O método de interpolação utilizado foi o inverso da distância ao quadrado (IDW). Os dados foram analisados a partir de uma abordagem regional, levando em consideração as "regiões de influência" no espaço interno do estado, hierarquias na rede urbana sul-rio-grandense e de conhecimentos sobre as dinâmicas da mobilidade urbana regional e no espaço das cidades. Finalmente, considerou-se a importância de certos aspectos inerentes ao ambiente de trabalho de determinadas atividades produtivas, na escala local, como fator de ampliação da dispersão do patógeno, especificamente, o ambiente climatizado dos frigoríficos.

\section{RESULTADOS E DISCUSSÃO}

Tal como se exibe na literatura, mobilidade, transportes e saúde pública são temas com forte correlação a partir de distintos vieses (GUTIERREZ, 2009). Relações importantes são observadas também entre a problemática em questão e as condições internas de espaços fabris, os quais, no contexto de pandemia da COVID-19, se conformam como pontos de disseminação interpessoal de patógenos, que saltam escalas na rede urbana através dos transportes. Os transportes rodoviários de passageiros e cargas que circulam pelas tessituras formadas pelas rodovias nacionais, estaduais, vias vicinais, vias expressas metropolitanas, terminais rodoviários, pontos de parada para lanches, aeroportos - bem como o próprio espaço interno dos veículos - são agentes de "espalhamento" de patógenos na escala estadual. Contudo, é importante ressaltar que mais do que meros deslocamentos, tratam-se de interações espaciais (ULLMAN, 1974; CORRÊA, 1997; COCCO \& SILVEIRA, 2011).

Desde 1997, quando Corrêa (1997) problematizou o conceito de interações espaciais de E. Ullman (1974; 1956), muito se tem discutido sobre a questão. O texto de Corrêa aborda as interações espaciais como sendo uma ampla circulação de bens, serviços e pessoas, em diferentes escalas e padrões, que culminam em um processo de transformação social, dentro do ciclo de reprodução do capital (CORRÊA, 1997). Destaca ainda, como resultado da evolução do capitalismo, a crescente "interdependência entre cidades e áreas, expressa por interações (...) (p.283)", que ocorre em uma cada vez mais complexa divisão do trabalho em diferentes escalas.

Contudo, mais do que meros deslocamentos que participam da realização do capital como "mônadas" - que cooperariam, uma a uma, na engrenagem da reprodução capitalista - a interação remete à 
necessidade do contato interpessoal para que se ampliem as inovações. É nesse contato que elementos contrários interagem, revolucionando suas forças produtivas (COCCO; SILVEIRA, 2011; CHEPTULIN, 1982). Esse caráter fortemente dialético da interação de pessoas, mercadorias, meios de produção, meios de reprodução social etc., traz uma ampla dificuldade de se fazer cessar os deslocamentos, mesmo que temporariamente, em uma economia capitalista periférica sujeita ao neoliberalismo. Noutros termos, os transportes não são um fim em si mesmo, mas atendem ao conjunto de atividades produtivas e de reprodução social que se organizam na forma de uma determinada divisão territorial do trabalho.

Essa divisão do trabalho remete ao ciclo de reprodução do capital, que se concretiza através de diferentes cadeias de produção e reprodução social (JARAMILLO, 1983), as quais variam em qualidade e quantidade nas diferentes formações socioespaciais (SANTOS, 1982). O dado contundente é que se trata de um contexto de pandemia da COVID-19, com a instituição de quarentenas e confinamento social, sobrepostas a uma crise econômica que já se avizinhava de modo quase concomitante.

No Brasil, muitas dessas cadeias de produção cessaram, ainda que parcialmente, enquanto outras continuaram plenamente e outras, foram ampliadas. Mas todas as atividades que continuam ocorrendo total ou parcialmente representam uma ameaça de dispersão do vírus? Vejamos o caso do estado do Rio Grande do Sul (Mapa 1).

Mapa 1 - Rio Grande do Sul Infraestrutura de transportes e distribuição do COVID-19 em 30 de abril de 2020.
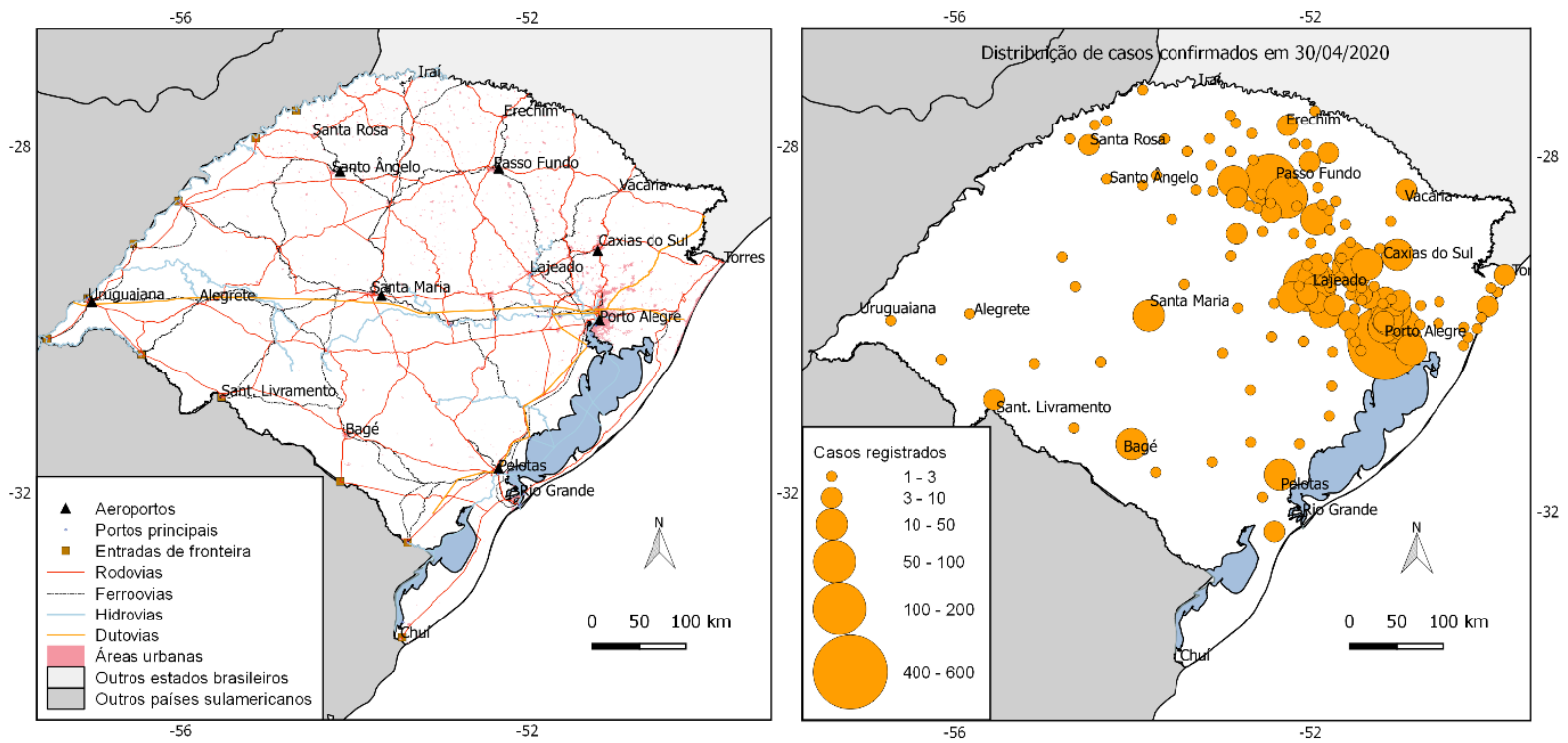

Fonte: Elaborado por Erika Collischonn, 2020

Em uma primeira aproximação, é possível observar (Mapa 1) que há "manchas" de característica regional com confirmação de contaminação pela COVID-19. Trata-se, relativamente, da lógica das "regiões de influência", com as cidades principais da rede urbana estadual atuando como centros dispersores do vírus. Nota-se, assim, ocorrências de contaminação em cidades que são pontos de interconexão de transportes rodoviários de passageiros e cargas; possuidoras de aeroportos em seu território e; sedes de distintas atividades produtivas. Quanto aos deslocamentos pendulares diários para o trabalho/consumo, podemos afirmar que estes têm sido responsáveis pelo aumento de casos intrarregionais da COVID-19 ${ }^{4}$. Vale ressaltar que os próprios centros de distribuição de mercadorias podem ser dispersores do Sars-CoV-2 no espaço interno das cidades, como é o caso dos

4 Essa constatação assevera a atualidade da regionalização como ferramenta de pesquisa, desde que empregada em uma abordagem mais próxima à hartshorniana. Há, portanto, complementaridades entre a ação de identificação de redes e sub-redes urbanas e a de regionalização.

DOl:http://dx.doi.org/10.14393/Hygeia0054406 $\quad$ Hygeia Edição Especial: Covid-19, Jun./2020 p.183 - 192, pág.186 
supermercados e atacadistas. Outros motivos de viagem também podem estar associados à essa dispersão 5 .

No que se refere aos transportes que viabilizam esses deslocamentos, vale salientar que o governo do estado do Rio Grande do Sul restringiu o transporte rodoviário interestadual por ônibus, sendo o intraurbano (espaço interno das cidades) e os intermunicipais por ônibus, liberados para operação com lotação máxima de $50 \%$ dos veículos. Além disso, não há restrição para a circulação com carro próprio, sistemas por aplicativo (Uber, Blablacar) e obviamente o transporte de cargas da produção agropecuária e industrial do estado. Na Região Metropolitana de Porto Alegre, nota-se que a contaminação se estende de Porto Alegre, ao longo do eixo da rodovia BR-116, no sentido de Caxias do Sul (Tabela 1; Mapa 2).

Tabela 1 - Municípios da Região Metropolitana de Porto Alegre com casos confirmados até dia 27 de abril de 2020

\begin{tabular}{|l|c|c|l|}
\hline \multicolumn{1}{|c|}{ Município da RMPA } & Casos Confirmados & Óbitos & \multicolumn{1}{c|}{ Eixo rodoviário } \\
\hline Porto Alegre & 427 & 12 & Entroncamento rodoviário/aeroviário \\
\hline Canoas & 21 & 1 & BR-116 \\
\hline Viamão & 20 & 0 & RS-040 \\
\hline Novo Hamburgo & 26 & 2 & BR-116 \\
\hline São Leopoldo & 27 & 1 & BR-116 \\
\hline Gravataí & 19 & 1 & BR-290 \\
\hline Alvorada & 11 & 1 & BR-290 \\
\hline Cachoeirinha & 9 & 0 & BR-290 \\
\hline Sapucaia do Sul & 8 & 0 & BR-116 \\
\hline Esteio & 7 & 0 & BR-116 \\
\hline Sapiranga & 7 & 0 & BR-116 \\
\hline Ivoti & 5 & 1 & BR-116 \\
\hline Triunfo & 5 & 0 & BR-386 \\
\hline Campo Bom & 4 & 0 & BR-116 \\
\hline Dois Irmãos & 3 & 0 & BR-116 \\
\hline Estância Velha & 3 & 0 & BR-116 \\
\hline Montenegro & 3 & 0 & RS-124 \\
\hline Charqueadas & 2 & 0 & BR-290 \\
\hline Eldorado do Sul & 2 & 0 & BR-116 \\
\hline Guaíba & 2 & 0 & BR-116 \\
\hline Santo Antônio da Patrulha & 2 & 0 & BR-290 e RS-474 \\
\hline São Sebastião do Caí & 2 & 0 & BR-116 e RS-240 \\
\hline Glorinha & 1 & 0 & BR-290 \\
\hline Rolante & 1 & 0 & BR-290 e RS-474 \\
\hline Taquara & 1 & 0 & BR-116 e RS-239 \\
\hline
\end{tabular}

Fonte: Secretaria da Saúde do Rio Grande do Sul/COVID-19. Disponível em:<http://ti.saude.rs.gov.br/covid19/>.

Nota-se ademais, a predominância de contaminações por proximidade com a capital, como é o caso de Viamão, Gravataí, Canoas, Alvorada, Guaíba, Novo Hamburgo, São Leopoldo, Esteio e Cachoeirinha, muito próximas a Porto Alegre e com típicos deslocamentos pendulares diários para o trabalho, estudos e consumos diversos. São nesses municípios que se observa o maior número de casos de COVID-19 da RMPA. No caso de uma região metropolitana, é importante destacar que se tratam de espaços com maior volume de fluxos diários de pessoas, em distintos modos de transporte,

\footnotetext{
${ }^{5}$ Por exemplo, deslocamentos relacionados à saúde, devido à distribuição regionalizada de hospitais segundo especialidades médicas. Além dos hospitais, há outros exemplos de equipamentos de alcance regional, com destaque para os serviços públicos, como é o caso das universidades. Se por um lado cessaram as mobilidades intraurbanas e pendulares das casas desses alunos até as universidades, tem ocorrido progressivamente movimentos desses estudantes de volta à casa dos pais ou parentes, para a redução de custos de moradia, alimentação etc., além das necessidades emocionais de proximidade destes em um contexto de comoção social. Vale ressaltar que mesmo com a controversa liberação paulatina das atividades por alguns governadores, é relativamente consensual a manutenção do fechamento das escolas e universidades, pelo alto volume de deslocamentos diários que essas atividades implicam.
} 
bem como com uma alta frequentação de espaços climatizados artificialmente (ar-condicionado), como grande supermercados (dotados de câmaras frias, inclusive), além de bancos, restaurantes e outros equipamentos.

É importante destacar que os pontos nodais de contaminação, com maior quantidade de casos de COVID-19, correspondem aos pontos de interconexão de transportes rodoviário e aeroviário do estado, que além da capital do estado, também se localizam em cidades como Caxias do Sul, Bagé, Passo Fundo, Santa Maria, Pelotas, Uruguaiana, Santo Ângelo, Santana do Livramento, Santa Rosa e Erechim, o que também está fortemente correlacionado às atividades produtivas e de reprodução social desses espaços. Veja-se o caso de Caxias do Sul e das cidades do entorno, dotadas de um caráter fortemente industrial - e a presença de indústrias insumidoras de mão de obra - onde o risco de contaminação é ampliado. Vale ressaltar que muitas fábricas da região já restringiram total ou parcialmente sua frequentação através de férias coletivas e outras medidas (caso da Agrale, Marcopolo, Random, Tramontina etc.). Observam-se 47 casos de COVID-19 em Caxias do Sul e outros 50 no conjunto do entorno da cidade (Bento Gonçalves com 17, Farroupilha 11, Garibaldi 11 e Carlos Barbosa 11).

Além da correlação existente entre casos de COVID-19 e as regiões mais ligadas às atividades industriais e de serviços (RMPA, Região da Serra Gaúcha) - que, ademais, são centros dispersores inter-regionais do vírus, pois concentram os nós rodoviários e aeroviários do estado do Rio Grande do Sul - são necessários esforços de análise para outras regiões do estado. Destacam-se, nesse caso, as produções agropecuárias e sua cadeia produtiva.

O Rio Grande do Sul tem exibido valor crescente de sua produção agropecuária, a qual representa $11,6 \%$ do $V A B$ nacional ${ }^{6}$, o que faz estas atividades serem importantes para a análise, já que mobilizam significativa quantidade de trabalhadores. Segundo levantamento realizado pelos técnicos da FEE-RS, em 2017, do Valor Bruto da Produção da pecuária gaúcha, um terço referia-se à produção de frangos (34,1\%); a segunda principal atividade foi a produção de bovinos $(22,0 \%)$, seguida pela produção leiteira $(21,4 \%)$ e pela suinocultura $(17,7 \%)$.

A criação de aves para o abate no estado, se concentra nas regiões da Serra e do Vale do Taquari que, conjuntamente, respondem por cerca da metade do Valor Adicionado Bruto dessa atividade no estado. A atividade também é relevante em municípios situados nas regiões do Vale do Caí, da Produção e ainda, as do Norte, Nordeste e Alto Uruguai, que apresentam maior integração com as plantas de abate situadas em Santa Catarina. Na criação de suínos para o abate, também havia duas regiões de concentrações: a primeira delas constituída por Vale do Taquari, Serra e Vale do Caí; a segunda, constituída pelos municípios da região Alto Uruguai que similarmente à avicultura está mais integrada com Santa Catarina (FEIX, LEUSIN Jr, AGRANONIK, 2017, p.30).

Para a análise das atividades agropecuárias que potencialmente são dispersoras do vírus, devemos considerar a temperatura dos ambientes nos quais são desenvolvidas, em maior ou menor medida propícios à disseminação viral. Nesse caso, destacam-se as baixas temperaturas de frigoríficos e abatedouros de porcos e frangos, a movimentação de pessoas para apanha, abate e beneficiamento dos animais, criando interações espaciais, principalmente no Norte e Nordeste do estado (Mapa 2).

Vale ressaltar que é justamente nas regiões do Vale do Taquari, da Serra, do Vale do Caí e Alto Uruguai, no Norte e Nordeste do estado, que se encontram significativa parte dos frigoríficos e abatedouros de suínos e frangos do estado. Nessas regiões, destacam-se casos confirmados de COVID-19 em Passo Fundo (102 casos), Lajeado (51 casos), Marau (49 casos), Carazinho (12 casos), Serafina Corrêa (8 casos), Taquari (12 casos), Erechim (5 casos), Harmonia (5 casos) e Muçum (2 casos), considerando as quantidades mais expressivas.

\footnotetext{
${ }^{6}$ Valor Bruto de Produção é uma expressão monetária da soma dos bens e serviços produzidos em determinado território econômico, num dado período de tempo. Essa variável não é a mais indicada para o acompanhamento da atividade econômica e a determinação da renda, pois não deduz os custos dos insumos utilizados na produção. 
Mapa 2 -Distribuição territorial dos principais frigoríficos no estado e Incidência da COVID-19 por município em 02 de maio de 2020
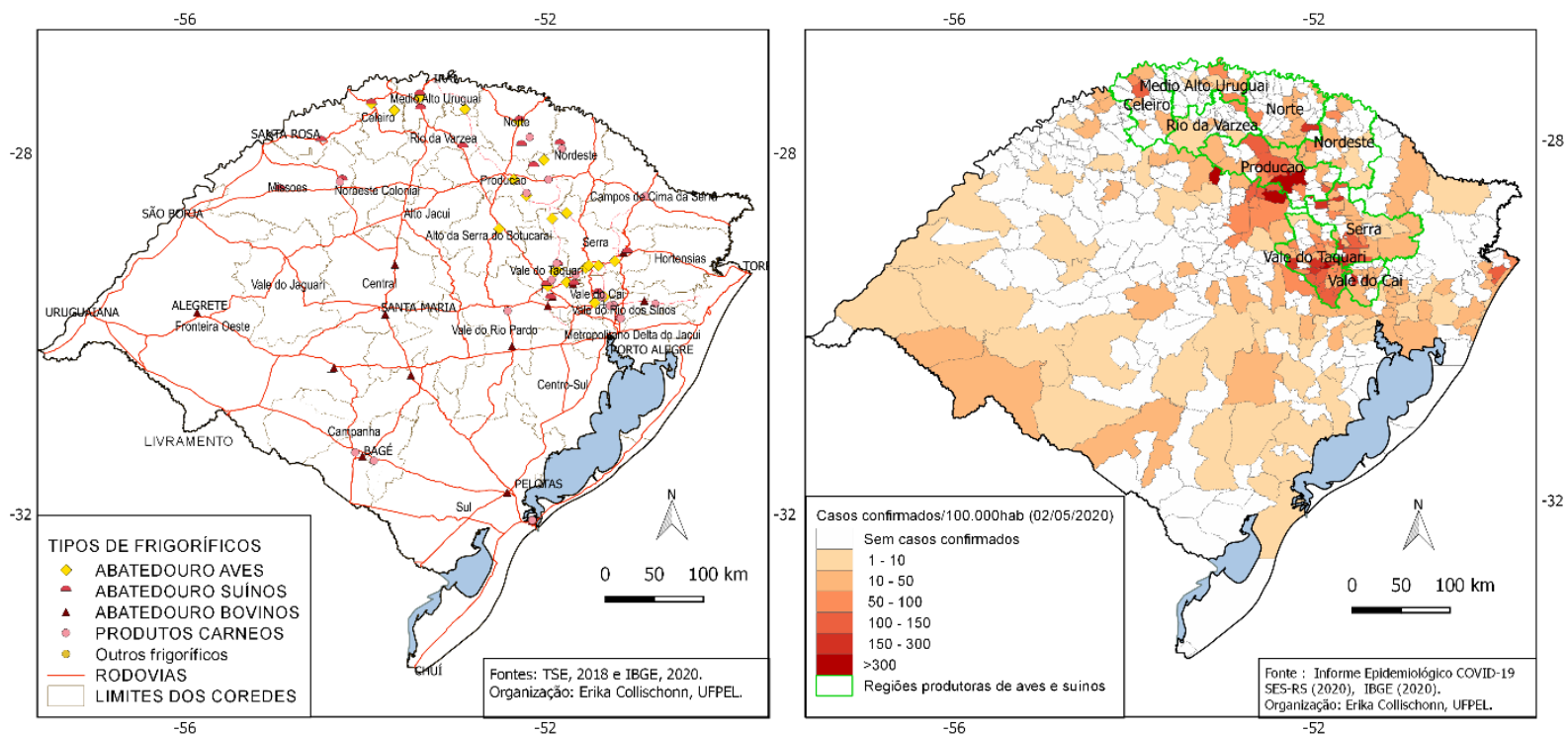

Fonte: Elaborado por Erika Collischonn, 2020.

Casos como o de Passo Fundo e de municípios menores do entorno, como Marau e Serafina Corrêa, nos quais há trabalhadores empregados nessas atividades, são exemplares da relação existente entre as atividades de abate e processamento de carnes, a contaminação por contato interpessoal e especificidade da temperatura desse tipo de ambiente de trabalho. A correlação entre o quantitativo de casos e a população dessas cidades é um dado relevante. Observa-se, por exemplo, incidências que variam de 20 a 300 casos para cada 100.000 habitantes, nessas regiões, o que as coloca em superioridade, nesse quesito, inclusive à RMPA (Região Metropolitana de Porto Alegre). Nesses casos, também deve-se considerar que a dispersão intermunicipal do SARS-CoV-2, ocorre em função de deslocamentos pendulares de muitos trabalhadores, do município de localização dos abatedouros/frigoríficos, para suas cidades de moradia, o que explica novas ocorrências, nos municípios menores do entorno dessas atividades.

Os casos de COVID-19 nas regiões da Fronteira Oeste, Campanha Gaúcha e Sul do estado têm destaque nos municípios localizados ao longo do eixo em que a rodovia BR-293 cruza com outro eixo rodoviário, quais sejam, Bagé (29 casos), Uruguaiana (3 casos), Santana do Livramento (9 casos), Pelotas (13 casos) e Rio Grande (4 casos). Essas regiões são tradicionalmente associadas à pecuária bovina, como sendo uma característica de sua formação sócio-espacial. Nota-se que Bagé e Santana do Livramento tiveram uma incidência precoce da doença. Finalmente há Santa Maria, na região central do estado, com 22 casos confirmados, cuja cidade se localiza no entroncamento rodoviário entre a BR-158, RSC-287/BR-287 e BR-392, além de possuir aeroporto regional com voos diários para Porto Alegre e a Base Aérea, que recebe voos militares de todo o país, o que também são fatores de difusão do vírus.

Um acompanhamento da difusão espaço-temporal dos casos confirmados no Rio Grande do Sul desde os primeiros casos, permitiu fazer um mapeamento deste processo (Mapa 3), com o intuito de compreender possíveis rotas de dispersão. Assim, onde o mapa está mais verde, ainda não havia se registrado casos na data; já nas áreas em que o tom passa ao amarelo e ao vermelho, significa que já se registraram casos há mais tempo.

Os primeiros casos ocorreram na Região Metropolitana de Porto Alegre, portanto, aí aparecem os primeiros pontos vermelhos já no dia 06/04/2020, quando em Porto Alegre, Campo Bom e Ivoti já haviam sido registrados casos há mais de 28 dias. A partir do segundo mapa, começa a se constatar a importância de algumas estruturas espaciais que explicam o que vai ocorrer no interior do estado, como os centros regionais e os eixos rodoviários já mencionados, que foram dispersores do vírus. $\mathrm{Na}$ metade norte do estado que é mais povoada, os caminhos de dispersão começaram claramente a aparecer já a partir do dia 13 de abril de 2020. No final de abril, boa parte dos municípios da Serra, DOl:http://dx.doi.org/10.14393/Hygeia0054406 $\quad$ Hygeia Edição Especial: Covid-19, Jun./2020 p.183 - 192, pág.189 
Vale do Taquari, Vale do Caí e Região de Produção, tinham casos há mais de três semanas. Assim, estas áreas passam a configurar em tons amarelos e alaranjados no mapa.

Enquanto isso, na Fronteira Oeste e no Noroeste, onde algumas cidades tiveram casos precocemente, como Alegrete e Santiago, não houve maior dispersão de casos em abril. Nestas áreas, o isolamento social das classes mais abastadas é favorecido porque as pessoas vão viver nas suas fazendas. Além disso, a própria dimensão dos municípios nesta parte do estado e a menor densidade demográfica não favoreceram a dispersão do vírus para outros municípios. Até o final de abril de 2020, para parte dos municípios do Oeste e Noroeste do estado, não havia registro de casos. Permaneceram em verde, ou seja, sem registro de casos até o final de abril, o extremo sul e o litoral médio. Por fim, vale registrar o avanço de casos de COVID-19 também no litoral norte do estado, no eixo da rodovia BR-101 entre os municípios de Torres e Osório, exemplares da difusão do vírus através de eixos rodoviários.

Mapa 3 - Evolução da COVID-19 no Rio Grande do Sul de 6 a 27 de abril de 2020

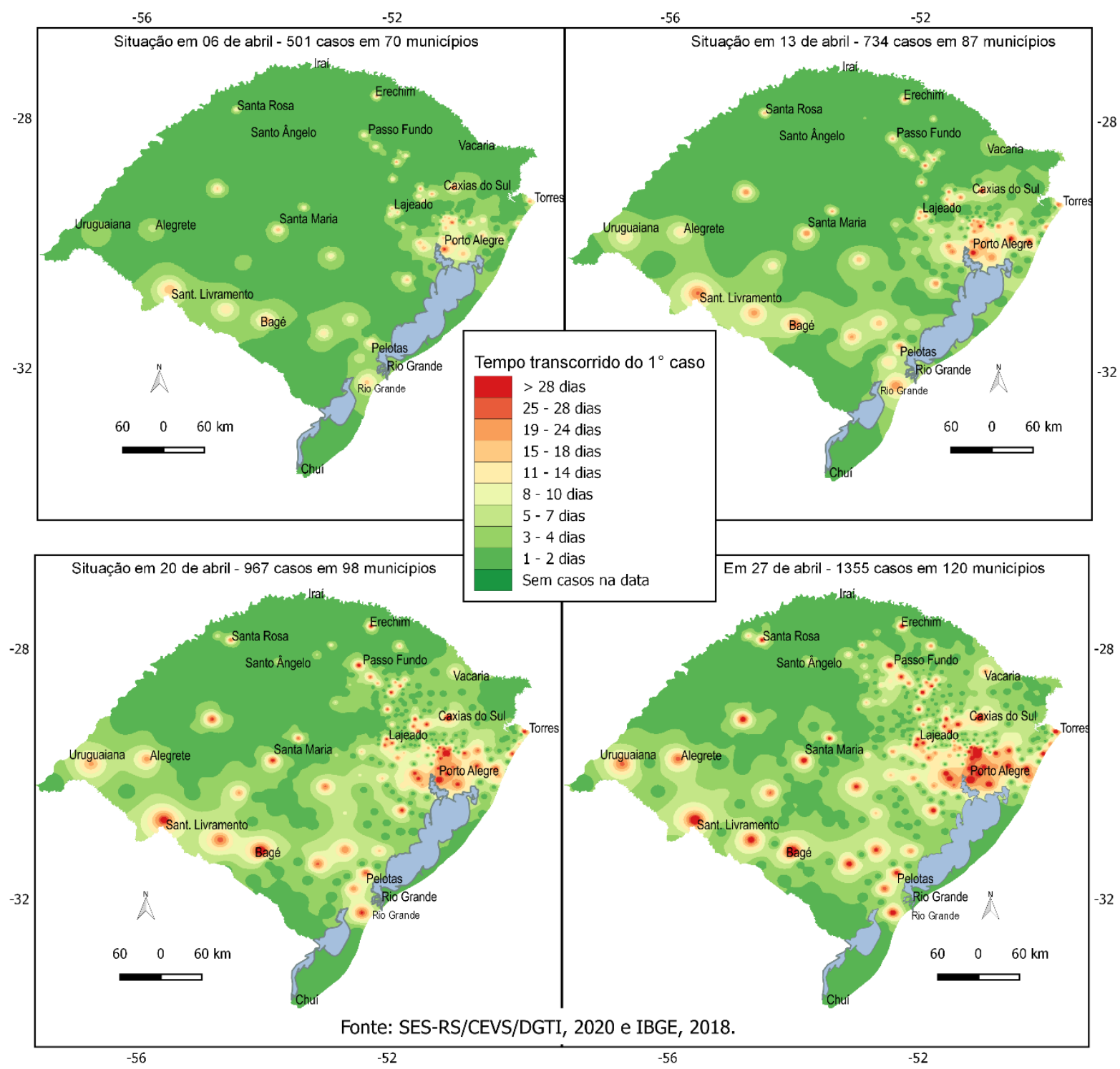

Fonte: Elaborado por Erika Collischonn, 2020. 


\section{CONSIDERAÇÕES FINAIS}

Os padrões espaciais de ocorrência da COVID-19 no estado do Rio Grande do Sul relacionam-se a uma conjugação de características distintas das diferentes regiões do estado, bem como às dinâmicas de suas interações espaciais. A entrada do novo coronavírus no estado, através de interações espaciais ligadas a viagens de negócio e turismo, por transporte aéreo, a países como Itália, Emirados Árabes, Holanda, entre outros, teve como ponto de dispersão a capital Porto Alegre, por sua condição de hub estadual, tanto aéreo quanto rodoviário. Assim sendo, a capital do estado é o ponto nevrálgico de transmissão comunitária, que se dá através de transportes aéreos regionais e transportes rodoviários. Contudo, as atividades econômicas que demandaram as interações espaciais que deram origem à entrada do patógeno no estado, não necessariamente tiveram origem em Porto Alegre. Há uma série de atividades econômicas de grande importância e que demandam contatos internacionais cuja planta produtiva se baseia em outras regiões do estado. É o caso da Serra Gaúcha e suas atividades industriais; do Vale do Taquari, da Serra, do Vale do Caí e Alto Uruguai, no Norte e Nordeste do estado, onde se encontram significativa parte dos frigoríficos e abatedouros de suínos e frangos do estado, com notória vinculação ao comércio internacional e, as regiões da Fronteira Oeste, Campanha Gaúcha e Sul do estado, com uma concentração de bovinos guiados para o abate.

Observou-se que há forte correlação entre essas produções e a ocorrência de casos de COVID-19. Nos casos das regiões com maior presença de frigoríficos e abatedouros, notou-se uma relação ainda mais intensa, baseada na incidência de casos de COVID-19 para cada 100.000 habitantes, em situação mais grave do que a própria Porto Alegre e a RMPA em geral. Conclui-se assim, que há espaços de transmissão interpessoal fortemente relacionados à temperatura do ambiente e sua climatização artificial (baixas temperaturas exigidas no processamento de carnes). Outros pelo contato na produção intensiva em mão de obra, mas também por um ambiente industrial severo para o sistema respiratório (poeira, ressecamento das vias aéreas pelo ambiente de trabalho, umidade, ambiente fechado de certas fábricas etc.).

Em stricto sensu, o efeito desses fatores é ampliado pela difusão espacial do vírus através dos transportes, entroncamentos rodoviários e aeroviários e o próprio ambiente interno dos veículos, sob climatização artificial. Como se pôde observar, não se trata de uma sequência de movimentos aleatoriamente realizados no espaço, mas de interações espaciais que remetem a um conjunto de cadeias produtivas, cuja totalidade reproduz o modo de produção capitalista, segundo as peculiaridades das distintas formações econômicas e sociais nas regiões. Essas interações espaciais remetem a uma complexa interdependência entre agentes. $O$ fato contundente é que a ruptura momentânea dessa interdependência exigiria ações do Estado de grande envergadura para a proteção social e sanitária, tanto das mobilidades que foram cessadas, como forma de reduzir os níveis de contaminação, quanto daquelas cujo caráter de combate à COVID-19 faz com que sua continuidade seja essencial (pessoal de saúde, pesquisadores, setores varejistas de comércio de alimentos e medicamentos, defesa civil e corpo de bombeiros etc.).

Finalmente, vale ressaltar que tanto nos espaços das cidades, das aglomerações urbanas (metropolitanas ou não) e na rede urbana estadual do Rio Grande do Sul, de modo mais amplo, o capital ditou as estruturas, funções, processos e usos das formas. Mesmo que parte significativa das rugosidades tenham sido mantidas, a concentração e a ampliação da mobilidade passaram a ser características comuns não apenas às áreas metropolitanas, mas a todas aquelas que polarizam e são polarizadas, dentro da tessitura da rede urbana e suas diferentes atividades produtivas. Essas mobilidades perfazem o caminho das divisões territoriais do trabalho das atividades econômicas em diferentes escalas e, por isso, a dispersão do vírus e a ocorrência da COVID-19 segue trajetórias relativamente semelhantes.

\section{REFERÊNCIAS}

BRASIL. Ministério da Agricultura, Pecuária e Abastecimento (MAPA). Relação de Estabelecimentos Frigoríficos, 2018. Secretaria de Defesa Agropecuária - DAS. Departamento de Inspeção de Produtos de Origem Animal - DIPOA. Serviço de Inspeção Federal - SIF. Disponível em:< https://www.abrafrigo.com.br/index.php/links-uteis/ > Acesso: 30/04/2020

BRENNER, Neil. State theory in the political conjuncture: Henry Lefebvre's "Comments on a new state form". Antipode. 2001, vol. 33, p. 783-808. https://doi.org/10.1111/1467-8330.00217 
CASAS, Nila P. R. O complexo industrial de saúde na área farmacêutica: uma discussão sobre inovação e acesso no Brasil. 236 f.. Tese (Doutorado em Saúde Pública) - Escola Nacional de Saúde Pública, FIOCRUZ, Rio de Janeiro, 2009.

CHEPTULIN, Alexander. A dialética materialista. São Paulo: Alfa-Ômega, 1982.

COCCO, R.G.; SILVEIRA, M.R. Basis for a materialist and dialectical approach to spatial interactions. Terrae. 2011, vol. 8, n. 2, p. 35-41.

CORRÊA, Roberto L. Interações Espaciais. In CASTRO, Iná E. de, GOMES, Paulo C. C., CORRÊA, Roberto L. (Org.). Explorações geográficas. Rio de Janeiro: Bertrand Brasil, 1997. p. 279-314.

FEIX, R. D.; LEUSIN JÚNIOR, S.; AGRANONIK; C. Painel do agronegócio no Rio Grande do Sul - 2017. Porto Alegre: FEE, 2017.

GADELHA, C.A.G. Desenvolvimento, Inovação e Saúde: perspectiva teórica e política do Complexo Econômico-Industrial da Saúde. Revista Ciência e Saúde Coletiva, n. 23, 2018. https://doi.org/10.1590/1413-81232018236.06482018

GUTIERREZ, Andrea. Movilidad y acceso: embarazo y salud pública em la periferia de Buenos Aires. In: CONGRESSO LATINO-AMENRICANO DE TRANSPORTE PÚBLICO - CLATPU, 15, 2009, Buenos Aires. Anais do XV CLATPU... Buenos Aires: CLATPU. Disponível em: http://www.filo.uba.ar/contenidos/investigacion/institutos/geo/ptt/GutierrezClatpu09a.pdf. Acesso em: 2 jan. 2017.

JARAMILLO, Samuel. Crisis dos medios de consumo colectivo urbano y capitalismo periférico. Desarrollo y Sociedad, vol. 12, n. 3, p. 127-145, 1983. https://doi.org/10.13043/dys.12.2

QGIS Development Team, <2018>. QGIS Geographic Information System. Open Source Geospatial Foundation Project. http://qgis.osgeo.org

SANTOS, Milton. Sociedade e espaço: a formação social como teoria e como método. Boletim Paulista de Geografia, 1982.

SPOSITO, M.E.B.; GUIMARÃES, R.B. Porque a circulação de pessoas tem peso na difusão da pandemia. Disponível em:

<https://www2.unesp.br/portal?fbclid=IwAR1q453zE8xiYBP6UBL3NcBI9G2GXRGBB2Qj-

Ik1DOUOPgNOjysiqbLkOj8\#!/noticia/35626/por-que-a-circulacao-de-pessoas-tem-peso-na-difusaoda-pandemia>.

ULLMAN, Edward. Geography as spatial interaction. In: HURST, Michael Eliot (Org.). Transportation Geography. Londres: Macgraw Hill, 1974, p. 29-39. 